\title{
Responsabilidad profesional: máximos, mínimos, excelencia y veracidad
}

\author{
G ustavo Figueroa C. \\ Professional responsibility: maximal, \\ minimal, excellence and veracity
}

Professional responsibility provides the groundwork for medicine since the existence of the Hippocratic Oath. Physicians must be prepared to justify their decisions and actions, based on scientific issues but also considering the underlying professional responsibilities. Ethical theories form a major part of such justification. A number of competing ethical theories may be identified. The maximal, minimal and excellence ethical theories agree with our experience with moral uncertainties. But veracity ethics is a new form of answering moral questions. Clinical situations are unavoidably conflictive. Lucid understanding of the necessary character of these conflicts leads to self-recognition and the itinerary of veracity ethics runs from misunderstanding to recognition. The self-awareness that veracity offers to physicians is difficult and painful due to the narcissistic humiliation that it inflicts on them (Rev Méd Chile 2006; 134: 233-9).

(Key words: Ethical aspects; Ethics; Moral obligations; Social responsibility)

Recibido el 4 de marzo, 2005. Aceptado el 26 de julio, 2005.

Departamento de Psiquiatría, Escuela de Medicina, Universidad de Valparaíso.

L a profesión médica se consolidó hacia la época de Hipócrates y se desarrolló de manera espectacular hasta la segunda mitad del siglo XX. Sucesos procedentes de distintas fuentes la remecieron como profesión: inundación tecnológica, intromisión de los poderes del mercado y estado, explosión de litigios por los usuarios, perversión de la relación-de-ayuda desde la virtuosidad médica hacia una postura timorata de no-maleficencia ${ }^{1}$. Finalizando el milenio, la frustración, incertidumbre y desmoralización amenazan con hacerla

Correspondencia a: Dr. Gustavo Figueroa C. Casilla 92-V, Valparaíso. Avenida Libertad 529 Depto. 701, Viña del Mar. Fono/fax: (32) 508550 - (32) 693671. E mail: gufigueroa@vtr.net sucumbir en un pragmatismo y escepticismo sobre la verdad característicos del pensamiento actual $^{2}$.

Nuestro punto de partida: lo que está en cuestión es la ética inherente a la responsabilidad profesional. La profesión se rigió por distintas concepciones éticas que -tácitas- la sustentaron desde el Juramento Hipocrático. Sin embargo, por no haber examinado intelectualmente esta base bioética ha resuelto insuficientemente su vertiente profesional. Este trabajo se divide en tres partes: después de investigar el reciente profesionalismo médico», analizaremos los tres fundamentos de la responsabilidad porque son el supuesto moral que está respaldándola. Finalizaremos con una historia clínica que expone nuestra propuesta: como con- 
ciencia, el médico no sabe de sí mismo de modo inmediato y así malinterpreta regularmente algunas elecciones, por lo que la veracidad, como postura ética originaria, asume el autoengaño para superarlo en reconocimiento auténtico de sí.

Proyecto profesionalismo médico. Preocupadas por las tribulaciones de la profesión, tres federaciones médicas propusieron reformar los sistemas de atención de salud bajo la noción de profesionalismo: colocar el interés del paciente por encima de los del médico, establecer estándares de competencia e integridad, proveer asesoría experta a la sociedad sobre asuntos de salud ${ }^{3}$. Concretamente, reivindicar a la medicina como profesión científico-humanista para satisfacer su compromiso con los enfermos y la sociedad ${ }^{4}$.

Un examen cuidadoso demuestra que los sprincipios»y «conjunto de responsabilidades»responden sólo a una operacionalización de las máximas que ha establecido la bioética americana (Tabla 1) ${ }^{5}$. El problema se desplaza, pues, a la bioética, sin mencionar que «humanismo médico» es un concepto impreciso y cuestionable ${ }^{6}$. Pero es sabido que sus propuestas carecen de sprincipios éticos básicos» porque, aunque así los denomina, el propósito de la National Commission se limitó a entregar juicios generales que sirven como justificación básica para las muchas prescripciones y evaluaciones éticas particulares»». Esto significa que se requiere una etapa previa: la razón moral de los fundamentos de la responsabilidad.

Responsabilidad profesional. Zubiri precisó las bases antropológicas de la diferencia entre responder y ser-responsable ${ }^{8}$. El animal responde a los estímulos porque hay una perfecta adaptación al emedio», contrariamente, el hombre es responsable porque no existe en íntima armonía con la naturaleza sino debe elegir o preferir entre las respuestas posibles: escoge un comportamiento en el «mundo». Mientras aquel vive en justeza», nosotros debemos justi-ficarnos, iustum-facere. Así, el hecho de la moralidad es una necesidad biológica inexorable de la condición humana por ser in-adaptada: dar cuenta ante sí o los demás razonadamente.

Gracia puntualizó que desde antiguo se distinguen dos tipos de responsabilidad. Mientras la primera es frente a sí mismo, la segunda es frente a los otros, la autoconciencia y la conciencia social. Aquella se guía por los proyectos de vida 0 ideales de perfección personales, ésta obedece a las obligaciones o mandatos colectivos. La una es

Tabla 1. Proyecto de profesionalismo médico (*)

\begin{tabular}{|ll|}
\hline $\begin{array}{l}\text { Principios } \\
\text { fundamentales }\end{array}$ & $\begin{array}{l}\text { Responsabilidades } \\
\text { profesionales }\end{array}$ \\
\hline \multirow{3}{*}{ Primacía del bienestar del paciente } & Compromisos \\
& $*$ Con la competencia profesional \\
Autonomía del paciente & $*$ A ser honestos con los pacientes \\
& $*$ Con la confidencialidad de los pacientes \\
Justicia social & $*$ De mantener relaciones apropiadas \\
& $*$ De perfeccionar la calidad de la atención \\
& $*$ Pe mejorar el acceso a la atención \\
& $*$ Por el conocimiento científico \\
& $*$ De mantener la confianza manejando los conflictos de \\
& $*$ intereses \\
&
\end{tabular}

(*) Adaptada de: Profesionalismo médico en el nuevo milenio: Un estatuto para el ejercicio de la medicina. Rev Méd Chile 2003; 131: 457-60. 
ley moral, la otra ley jurídica ${ }^{9}$. Siguiendo a Adorno sobre las experiencias de vida indigna que devastaron a la humanidad durante la guerra, Cortina, a su vez, estableció dos niveles éticos: uno superior, «esponsabilidad fuerte», que define los máximos morales a que tiene que aspirar el sujeto, los ideales privados de autorrealización, los sistemas de valores propios, su idea de vida virtuosa; uno inferior, «esponsabilidad débil», que determina los mínimos morales que necesita alcanzar cualquier individuo, el cumplimiento del deber que es exigible a todos por igual en el campo de las relaciones si éstas pretenden ser propiamente humanas, vida buena y vida correcta ${ }^{10,11}$. La «esponsabilidad de máximos» (la virtuosidad) comprende los principios de autonomía y beneficencia, y la «responsabilidad de mínimos» (el deber) los de justicia y no-maleficencia (Tabla 2).

Empero los máximos y mínimos han sido poco eficaces para el fomento de la ética profesional, por lo que se les ha sumado un modelo secular desencantado (Entzauberung) procedente del mundo empresarial ${ }^{12}$. Aunque los negocios han sido tradicionalmente value-free, ahora se acepta que sí son value-laden son referidos a dos valores: «calidad total»y excelencia» ${ }^{3}$. En salud, concebida como empresa de servicios, ambos valores requieren ser operativizados para que, actuando como dispositivos de autocontrol, eviten la mala práctica y perfeccionen el sistema y cuidado del enfermo ${ }^{9}$.

Por otra parte, profesión (professio) deriva del verbo profiteor que significa confesar abiertamen- te, proclamar, hacer voto. De ahí que su sentido es de confesión pública, promesa, consagración. La profesión médica ha guardado históricamente una relación íntima con la consagración religiosa (professio monastica) y por ello está investida por una fuerte responsabilidad moral y una impunidad jurídica total o relativa ${ }^{9}$. Lo contrario sucede a los oficios (officium): ob-facere es un hacer sin demora, lo que urge, la faena que se presenta como inexcusable, un deber, en el que no hay margen para decidir si se hace o no se hace, es incuestionable ${ }^{14}$. Su responsabilidad jurídica es máxima y la ética es mínima. Manifiestamente, la medicina moderna ha saltado vertiginosamente del estatuto de profesión al de oficio con la consiguiente mutación de sus responsabilidades. Por esto los litigios legales crecieron exponencialmente y seguirán multiplicándose si el médico continúa asumiéndose como técnico empresarial de la salud, mientras las virtudes están esfumándose o reduciéndose a comportamientos cautelosos no-maleficentes.

Se consiguió dar razón o fundamentar la profesión médica, pero falta una pregunta previa. El profesional ¿cuánto sabe de la moralidad de sus actos? Y lo que sabe ies adecuado? Una historia iluminará.

El sueño de Irma. En la noche del 23-24 de julio de 1895, Freud tuvo un confuso sueño que, posterior a un dificultosísimo autoanálisis, reveló que tras la figura de Irma se escondían cuatro enfermas diferentes, que habían sufrido sendos

Tabla 2. Ética de la profesión médica

\begin{tabular}{|lcc|}
\hline Ética de máximos & Ética de mínimos & Ética empresarial \\
\hline Responsabilidad moral & Responsabilidad jurídica & ¿Value-free? \\
Autonomía & Justicia & \\
Beneficencia & No-maleficencia & \\
Valores personales & Leyes de la sociedad & Técnicas eficaces \\
Ideales de la conciencia & Preceptos válidos para todos & Eficiencia costo-beneficio \\
Virtudes íntimas & Virtuosismo objetivo & Destreza \\
Principialismo & Consecuencialismo & Utilitarismo \\
Profesión & Oficio & Técnico \\
Impunidad & Penalización & Penalización \\
\hline
\end{tabular}


errores médicos, cometidos por Breuer, Fließ y él ${ }^{15-17}$. El más grave había ocurrido cinco meses antes: Fließ, como otorrinolaringólogo, había operado de los cornetes a Emma Eckstein, paciente y amiga de Freud, sin la experiencia necesaria y siguiendo una teoría médicamente no acreditada; viviendo en otra ciudad distante, la abandonó dejándole, inadvertidamente, medio metro de gasa que continuó supurando y sangrando profusamente, hasta casi provocarle la muerte por anemia aguda un mes después, en el momento de ser extraída por casualidad, en aquel instante de la extracción, Freud de inmediato quiso reprochárselo a Rosanes» que la había ejecutado como interconsultor ${ }^{18-20}$. Más tarde, Freud mantuvo tercamente su opinión que la enferma era histérica y su hemorragia, a pesar de que al presenciarla él casi se desmayó, fue causada por deseos inconscientes de reconocimiento $\mathrm{y}$, ulteriormente, incluso pretendió poseer pruebas irrefutables. Rápidamente le ratificó a Fließ que nadie te hace un reproche, además yo no sabría por qué», y todavía spara mí sigues siendo el doctor en cuyas manos uno deposita confiadamente la propia vida y la de los suyos» (20.4.1895) ${ }^{21}$. Freud intuyó oscuramente que algo semejante le había sucedido a Breuer con Berta Pappenheim hacía trece años y a él con Anna Hammerschlag y Sophie Schwab-Paneth ${ }^{22-24}$. Los deseos ocultos del sueño son inequívocos: Freud no fue responsable, sino otros, del permanecer enferma de Irma (la misma Irma, un colega) y, simultáneamente, es absuelto totalmente de las propias negligencias por Fließ y otro médico. Su postulado teórico - »el sueño es una satisfacción (inconsciente) de deseos (reprimidos) $\gg 5_{-}$se confirma en Freud mismo: su responsabilidad profesional queda intacta tanto como la de sus amigos Fließ y Breuer.

Sinopsis bioética. Las escenas del sueño son condensaciones de múltiples protagonistas y sucesos, por lo que las interconexiones Freud-FließBreuer-pacientes-circunstancias-clínicas son complejísimas, intercambiándose entre sí, según el sentido, los personajes y acontecimientos ${ }^{15-20}$. En su interpretación, Freud omitió información esencial por «discreción»-sólo el acudir a otras fuentes permitió reconstruirla fidedignamente ${ }^{22-24}$ - pero sobre todo, ignoró material decisivo sobre su propio proceder. En la Tabla 3 están formulados algunos dilemas morales del comportamiento de Fließ. Frente a éstos ¿cuánto y qué tipo de conocimiento tuvo Freud? Resulta innegable que no vio, mal interpretó o huyó ante ciertas responsabilidades profesionales que Fließ violó, fomentando que éste se sperdonara ese mínimo descuido ${ }^{21}$. Pero la rapidez en justificar al amigo, la necesidad reiterada de reafirmarle en su inocencia, el apremio en culpar a otro colega y aun a la paciente, el reprocharse por haberlo apoyado para operar lejos de su ciudad, el minimizar el riesgo vital para Emma, son indicadores que, simultáneamente, se percató -indirecta, simbólicamente- de la trasgresión de Fließ a los principios de beneficencia, no-maleficencia y autonomía.

En contraposición, ¿qué saber tuvo de su propia responsabilidad? Desconoció que el conflicto de lealtades entre paciente-médico lo resolvió en favor de Fließ: aceptó teorías no avaladas médicamente, propició la intervención a pesar de la lejanía del hogar del cirujano, responsabilizó a la histeria de la producción del cuadro, banalizó las responsabilidades médicas del compañero, distorsionó levemente los datos clínicos, no conminó al doctor a que se presentara durante el mes de empeoramiento de Emma. Sin reconocérselo, infringió sus ideales profesionales de máximos que lo distinguieron durante su vida ${ }^{25}$. Sin embargo, entrega alusiones disimuladas que apuntan inequívocamente a auto-reproches latentes generados por su conciencia culposa (ej.: al conectarlo con sus negligencias con Anna Hammerschlag y Sophie Schwab-Paneth).

En terminología de Weber ${ }^{12}$, Freud poseía interiormente una fuerte sética de la convicción» (Gesinnung) (máximos) que hacía que sus elecciones expresaran simultáneamente una estricta

\section{Tabla 3. Dilemas morales de Fließ ante los cuales se vio enfrentado Freud}

* Teorías no avaladas por la práctica médica

* Proponer operación sin poder vigilar su evolución inmediata (imprudencia)

* Negligencia (malpractice)

* Agresión física (battery)

* Abandono del cuidado 
〈ética de la responsabilidad»(Verantwortung) (mínimos). Empero hemos sospechado que Freud actuó con llamativa ambigüedad moral ante sí mismo y otros, siendo la más sorprendente jpor qué necesitó de un sueño para acceder a su verdad -esto es, oblicua, enmascarada, altamente desfigurada- y aun así sin lograrla plenariamente?

Cuánto sabe el médico de sí mismo. Profesión o Beruf tiene otro sentido en alemán. Weber señaló que está vinculada con Ruf, llamada, y Berufung, vocación ${ }^{12}$. En cuanto voca-ción (vocatio), es la llamada que hace la conciencia al sujeto con una voz interior (vocis) para que se atenga a sus ideales o proyectos íntimos. El dictado de la conciencia se expresa en obligaciones ${ }^{26}$. Ya dijimos que la medicina tiene una responsabilidad máxima o ética, y ahora entendemos que la detenta por ser vocación. La encargada de recordársela al profesional es la cum-scientia, conciencia moral, tribunal que somete a juicio las acciones personales para adjudicarles el valor de buenas o malas.

Pero el fundamento último del concepto de responsabilidad profesional radica en la ontología griega de la presencia (Anwesenheit): atenerse a lo dado y presente, que es conocido plena y adecuadamente por el individuo y, al conocerlo, queda a total auto-disposición ${ }^{27}$. Traducida a otros términos: el hombre como sujeto se representa a sí y el mundo como objeto (Vor-stellung), como imagen (Bild) que en su interior, concebido como escenario, se reproduce como vivencia: «al pasar a ser imagen, lo existente en su conjunto se coloca como aquello en que se instala el hombre, lo que, en consecuencia, quiere llevar ante sí, tener ante sí y de esta suerte colocar ante sí en un sentido decisivo ${ }^{28}$. En nuestro caso de ética profesional: estar frente a un tribunal (propio yo) que dictamina según una determinada exigencia (ley moral). Por un lado, el «yo juzgo»está preconcebido como un yo idéntico a sí mismo, que se auto-posee sin residuo, es responsable de sus actos porque dispone de su ser a su libre arbitrio, y es transparente para sí. Por otro, la obligación ética presupone leyes (Gesetz) puestas y propuestas (vorsetzen) por la medicina o la naturaleza delante de un sujeto que las aprehende tal como ellas son en sí, y con esto las refleja fiel, adecuada, límpidamente como espejo ${ }^{29}$.
Sin embargo, Freud 1) no tuvo conocimiento pleno e íntegro de sus deberes ante Irma, Fließ y él, vale decir, no pudo disponer de ellos a cabalidad como sistemas de representaciones objetivos. 2) Sobre todo, no consiguió un autoconocimiento acabado de sus deseos y terrores, no teniendo así un poder ilimitado sobre sus intenciones y ambiciones -no fue soberano sobre sí-, menos aún supo de su intimidad como unidad coherente de razones y pasiones referidas a su accionar profesional. 3) Contraria y sorprendentemente, Freud poseyó un determinado saber -alusivo, enmascarado, deformado- de su conducta profesional, pero conocimiento al fin, por lo que no podemos hablar sin más de ignorancia.

Estas tres características determinaron los cuestionamientos que llevaron a Nietzsche a hablar de des-posesión o des-centramiento del sujeto. Primero: «Contra el positivismo, que se detiene en los fenómenos: 'sólo hay hechos' - yo diría: no, precisamente no hay hechos, sino sólo interpretaciones. No podemos constatar ningún hecho en sí» $30 ;$ o en expresión próxima a nuestro tema: «a moral misma ha sido considerada como 'dada', [] una forma de creencia candorosa en la moral dominante,... lo contrario de un examen, análisis, puesta en duda de esta creencia» ${ }^{31}$. Segundo: «Nos hemos tomado tanto trabajo para aprender que las cosas exteriores no son lo que parecen, jbien, pues lo mismo ocurre en el mundo interior! Las acciones morales son en realidad 'algo más'...: todas las acciones nos son esencialmente ignotas »2; con palabras del Nachlass: «Mantengo el carácter puramente fenoménico igualmente del mundo interior: todo lo que se nos hace consciente es, de un extremo a otro, previamente arreglado, simplificado, esquematizado, interpretado, se nos oculta absolutamente, y quizás sean pura imaginación»30. Tercero: ¿cómo es posible no saber y saber al mismo instante? Para Nietzsche hay pocas dudas: las máscaras nos constituyen y es indispensable llevar a cabo desenmascaramientos, pero sabiendo que, aunque «de pronto desperté en medio de este sueño, sólo [fue para llegar] a la conciencia de que precisamente soñaba y de que tenía que continuar soñando, para no perecer 33; esto es, él sueña aunque ahora sabe que sueña y tiene que seguir soñando, porque no hay despertar definitivo posible, no existe el hombre translúcido total o conciliado consigo. 
Poco tiempo después -1897-, contrariamente a la concepción de un sí mismo auténtico que existe santes y aparte de todos los roles»), independiente de cualesquiera circunstancia individual 0 profesional $^{34}$, Freud finalmente admitió en él mismo un yo escindido, no unificado en una historia congruente y oficial, que «no es dueño ni siquiera en su propia casa» 35 . No fue su razón la que le puso en estado de alerta sino su pretensión de ser enteramente sincero conmigo mismo ${ }^{21} \mathrm{y}$ con sus negligencias médicas. Forzado a seguir cuestionándose por sus casos fallidos, concluyó que había una parte alienada en él mismo: se comportaba éticamente como si otra persona fuese la responsable de sus actos, como si alguien se hubiera deslizado debajo de su epidermis y poseyera propósitos y fines morales antagónicos o incongruentes. Lo que terminó por convencerle de aquello, ante lo cual su intelecto lúcido había permanecido ciego, fue la solución al enigma de Edipo en su propio ser ${ }^{19}$. Es el drama del reconocimiento-de-sí-mismo, esto es, del duro camino por recorrer que parte de la mala autocomprensión - del hombre pasado que él mismo había maldecido anteriormente con desprecio, arrogancia, soberbia- y se consuma en el autoconfesarse y asumirse: «o también soy ese hombre. En cierto sentido, siempre lo he sabido, pero en otro sentido no; ahora intentaré llegar a ser quien soy».

Responsabilidad profesional y veracidad. Hasta aquí la responsabilidad profesional se guiaba por máximos, mínimos o excelencia. Necesitamos además veracidad, vale decir, una ética del descubrimiento» de los motivos y finalidades que originan -oculta y encubiertamente- las elecciones y conductas profesionales.

1. La responsabilidad profesional radica ahora: ¿en qué estado de autoengaño-[distorsión]veracidad-[propiedad] nos encontramos en cada actuación médica? ${ }^{36}$.

2. A diferencia de la mentira, error o ignorancia, el autoengaño del profesional no es un evento casual sino constitutivo de su conciencia: es la estructura de mala-fe o descentramiento del sujeto en una multiplicidad de interlocutores válidos independientes entre ellos o no coincidencia radical consigo mismo ${ }^{34,37}$.
3. La ética de la veracidad es técnica de la verdad y no técnica de dominio: voluntad de acceder al discurso veraz y no al del control y subordinación a normas peculiares a la adaptación profesional. Así escapa a la objetividad, certeza y verificación mensurable, sólo tolera la aclaración o autodevelamiento, que a lo más es plausible, porque no existe la percepción privilegiada que capte, desde un punto imparcial y decisivo, las intenciones últimas que sustentan la responsabilidad, razón científica ante razón hermenéutica.

4. Es una tarea o trabajo ineludible del clínico, nunca definitivo y siempre personal e intransferible, pero no un fin: es des-ocultar por medio de la interpretación los móviles de cualquier decisión, interpretación que significa combatir resistencias, vencer oposiciones, superar defensas, «ejercer violencia, reorganizar, acortar, suprimir, llenar, imaginar ficciones ${ }^{38}$.

5. En tanto búsqueda que se aclara a sí mismo en su parte que no le pertenece, es diálogo: consigo mismo y con el otro, diálogo que promueve o impide la iluminación de aquello enajenado. La conciencia no es sólo autorreflexividad sino reciprocidad: autoconciencia y conciencia comunicativa ${ }^{10}$.

6. La ética de la veracidad no pregunta ¿qué médico soy yo real, esencialmente? sino ¿en qué tipo de médico me convierto si resuelvo seguir un determinado curso de acción?; tampoco ¿cuáles normas debo obedecer como profesional? sino ¿cuál es la autenticidad de mis acciones y obediencias?; menos aún ¿debo revelarle al paciente su diagnóstico ominoso? sino ¿cuán veraz es su petición para que le comunique su pronóstico?39.

7. Su valor es la sinceridad consigo mismo y el otro, su transgresión conlleva la culpabilidad interna antes que la penalización externa, es válido para sí y todos los involucrados, no se reduce a prescripciones sino a incitaciones para practicarla, no es una destreza ni un virtuosismo sino un hábito (ethós) producto del aprendizaje ${ }^{40}$ en las «durezas de la existencia profesional»e implica una humillación al narcisismo del médico de tener que someterse y acatar aquello que se escapa a su control. 


\section{REFERENCIAS}

1. Peilegrino ED. The metamorphosis of medical ethics. A 30-year retrospective. JAMA 1993; 269: 1158-62.

2. RORTY R. Hoffnung statt Erkenntnis. Eine Einführung in die pragmatische Philosophie. Wien: Passagen, 1994.

3. Profesionalismo médico en el nuevo milenio: Un estatuto para el ejercicio de la medicina. Rev Méd Chile 2003; 131: 457-60.

4. Rosselot E. Reivindicando la medicina como profesión científico-humanista. Rev Méd Chile 2003; 131: 454-5.

5. Beauchamp TL, ChILDRESS JF. Principles of biomedical ethics. $5^{\text {th }}$ ed. New York: Oxford University Press, 2001.

6. FigueroA G. ¿Al fin una medicina humanista? Rev Méd Chile 1999; 127: 94-100.

7. National Comission for the Protection of Human Subjects of Biomedical and Behavioral Research. The Belmont Report. Washington: DHEW Publications OS 78-0012, 1978

8. ZuBiri X. Sobre el hombre. Madrid: Alianza, 1986.

9. Gracia D. Profesión médica. Investigación y justicia sanitaria. Bogotá: El Búho, 1998.

10. Cortina A. Ética mínima. Introducción a la filosofía práctica. 3a edición. Madrid: Tecnos, 1992.

11. Adorno T. Minima moralia. Reflexionen aus dem beschädigten Leben. Frankfurt: Suhrkamp, 1951.

12. WeBer M. Politik als Beruf, Wissenschaft als Beruf. Berlin: Dunker \& Humblot, 1959.

13. Peters TJ, Waterman RH. En busca de la excelencia. Las lecciones de empresas mejor gestionadas de los Estados Unidos. Barcelona: Folio, 1992.

14. Ortega y Gasset J. Misión del bibliotecario. OC V; 1935: 207-34.

15. FreUd S. Die Traumdeutung. GW II/III 1900; 57-99.

16. AnzIEu D. Freuds Selbstanalyse und die Entdeckung der Psychoanalyse. 2 Bände. München: Verlag Internationale Psychoanalyse, 1990.

17. Grinstein A. Sigmund Freud's dreams. New York: International Universities Press, 1980.

18. SchuR M. Weitere «Tagesreste»zum «Traummuster». En: Scheidt Jv, Hrsg. Der unbekannte Freud. Neue Interpretationen seiner Träume. München: Kindler, 1974. p. 116-149.

19. FreUd S. Briefe an Wilhelm Fließ 1887-1904. Frankfurt: Fischer, 1986.

20. HirschmüLeR A. Physiologie und Psychoanalyse in Leben und Werk Josef Breuers. Bern: Hans Huber, 1978.
21. Freud S. Briefe 1873-1939. 2. Aufl. Frankfurt: Fischer, 1968.

22. APPIGNANESI L, ForRester J. Freud's women. $2^{\text {nd }} \mathrm{ed}$. New York: Other Press, 2000.

23. Schur M. Freud. Leben und Sterben. Frankfurt: Suhrkam, 1975.

24. HARTMAN FR. A reappraisal of the Emma episode and the specimen dream. J Am Psychoanal Ass 1983; 31: 555-85.

25. RuefF P. Freud: the mind of the moralist. New York: Harper and Row, 1966.

26. Zubiri X. El problema filosófico de la historia de las religiones. Madrid: Alianza, 1994.

27. Heidegger M. Überwindung der Metaphysik. En: Heidegger M. Vorträge und Aufsätze. 5. Auflage. Pfullingen: Neske, 1967; 67-95.

28. Heidegger M. Die Zeit des Weltbildes. Gesamtausgabe 5. Frankfurt: Klostermann, 1984; 69-104.

29. RoRTY R. Philosophy and the mirror of nature. Princeton: Princeton University Press, 1979.

30. Nietzsche F. Aus dem Nachlass der Achtzigerjahre. Werke in drei Bänden III. München: Hanser, 1966; 415-925.

31. NiETzsche F. Jenseits von Gut und Böse. Vorspiel einer Philosophie der Zukunft. Werke in drei Bänden II. München: Hanser, 1966; 563-759.

32. NiETzsche F. Morgenröte. Gedanken über die moralische Vorurteile. Werke I. München: Hanser, 1966; 1009-279.

33. NiETzsche F. Die fröhliche Wissenschaft. Werke in drei Bänden II. München: Hanser, 1966; 7-274.

34. RoRTY R. Freud and moral reflection. En: Rorty R. Essays on Heidegger and others. Philosophical papers II. Cambridge: Cambridge University Press, 1991; 201-28.

35. FREUD S. Vorlesungen zur Einführung in die Psychoanalyse. GW XI; 1916-1917: 1-497.

36. Figueroa G. La revelación del diagnóstico: el lugar de la beneficencia, autonomía y veracidad en la ética médica. Rev Méd Chile 1998; 126: 569-76.

37. Sartre J-P. L'Etre et le néant. Essai d'ontologie phénomenologique. Paris: Gallimard, 1943.

38. Nietzsche F. Zur Genealogie der Moral. Eine Streitschrift. Werke in drei Bänden II. München: Hanser, 1966; 761-900.

39. Figueroa G. La bioética en el diván. ¿Puede Freud ayudarnos en los dilemas de la ética médica? Rev Méd Chile 2004; 132: 1550-6.

40. Aristóteles. Ética a Nicómaco. Madrid: Centro de Estudios Constitucionales: 1981. 